\title{
ANÁLISE DO INVESTIMENTO EM CLIMATIZAÇÃO PARA BOVINOS DE LEITE EM SISTEMA DE ALOJAMENTO FREE-STALL
}

\author{
SILVIA R. L. SOUZA ${ }^{1}$, IRENILZA A. NÄÄ ${ }^{2}$, SIMONE KARASAWA ${ }^{3}$, \\ CARLOS E. B. ROMANINI ${ }^{4}$
}

\begin{abstract}
RESUMO: A dificuldade de adaptação das raças leiteiras européias no Brasil afeta diretamente o setor produtivo de leite. As condições climáticas do País são desfavoráveis, e o desenvolvimento de novas tecnologias é imprescindível para que o potencial genético e a capacidade de conversão alimentar sejam evidenciados nos animais. Dessa forma, a análise econômica do investimento na climatização de instalações do tipo free-stall torna-se necessária para estimar os aspectos relacionados à rentabilidade, capacidade de pagamento e tempo necessário para recuperar o capital investido. O objetivo deste trabalho foi o de avaliar a influência da climatização no processo produtivo de bovinos de leite e realizar uma análise econômica do investimento. Foram utilizadas 470 vacas com características genéticas e morfológicas homogêneas, de alta produção, analisadas em dois períodos semelhantes. Os cálculos do investimento foram efetuados por meio do programa Excell $\Theta$. Os resultados das análises indicam que deve haver retorno do capital investido em curto prazo (57 dias).
\end{abstract}

PALAVRAS-CHAVE: bovinos de leite, análise econômica, climatização.

\section{ANALYSIS OF THE INVESTMENT IN CLIMATIZATION FOR DAIRY COWS IN FREESTALL}

SUMMARY: The difficulty in adapting European dairy cows breeds in Brazil affect considerably the milk production sector. Brazilian climatic conditions are not totally favorable and the development of new tecnologies is needed for the animals express their genetic potential, as well as their best feed conversion. An economical analysis of the applied investment in the free-stall climatization equipment in dairy housing, for estimating studies related to profit, possibility of return investment as well as time for this return is necessary. The objective of this research was to evaluate the influence of climatization investment in the milk production process and analyze the economical aspect of this investment. There were used 470 high productive dairy cows with genetic and morphologic homogeneous characteristics, and analyzed in two similar periods. Investment calculations were done using Excell $\Theta$. The results were satisfactory and the invested capital was proved to return to the producer in a short term, 57 days.

KEYWORDS: dairy cows, economical analysis, cooling.

\footnotetext{
${ }^{1}$ Estudante de Mestrado, DECR/FEAGRI/UNICAMP, Campinas - SP, Fone: (0XX19) 3788.1039, Fax: (0XX19) 3788.1010, e-mail: silucas_souza@hotmail.com

${ }^{2}$ Profa. Titular., FEAGRI/UNICAMP, Campinas - SP.

${ }^{3}$ Estudante de Estatística, IMEC/UNICAMP, Campinas - SP.

${ }^{4}$ Estudante de Engenharia Agrícola, FEAGRI/UNICAMP, Campinas - SP.

Recebido pelo Conselho Editorial em: 12-10-2002

Aprovado pelo Conselho Editorial em: 5-5-2004
} 


\section{INTRODUÇÃO}

O leite é um alimento nobre e tem uma grande importância na nutrição básica de pessoas de várias idades. Com a adoção de novas tecnologias no setor leiteiro, esse poderá ser explorado cada vez mais e, com isso, obter um aumento considerável da produção. O Brasil é o sexto maior produtor de leite do mundo, e sua produção está crescendo a uma taxa anual de 4\% (VILELA, 2002). Em 1995, o rebanho tinha aproximadamente 16,5 milhões de cabeças, tendo um aumento em 2000 com uma produção de 19,8 milhões de cabeças de gado de leite. A maior parte do rebanho leiteiro está localizada nas regiões mais quentes do País. A quantidade de leite cru ou resfriado adquirido entre os meses de janeiro e setembro de 2001 correspondeu à produção de 9,6 milhões de litros de leite. Praticamente toda a produção leiteira do Brasil provém de sistemas semi-estabulados de criação (IBGE, 2001).

Métodos de manejo adequado, principalmente do gado leiteiro, poderão reverter em produção leiteira melhorada do rebanho. Em busca de melhor desempenho do rebanho, leva-se em consideração o clima em que ele se encontra. Os elementos climáticos influenciam no desempenho animal. Dessa maneira, deve-se atuar a fim de minimizar seus efeitos, utilizando construções adequadas para abrigá-los. Além disso, no Brasil, prevalecem as altas temperaturas associadas com altas umidades relativas.

Quando os animais estão abrigados, eles não sofrem os efeitos da radiação solar, cuja intensidade é determinada pela carga de radiação proveniente das redondezas. Se esses animais estiverem no pasto, recebem cargas de radiação provenientes do sol, da atmosfera, do horizonte e do solo (nu ou coberto). Quando abrigados, a carga de radiação incidente direta diminui, só que acrescida das cargas da sombra dos próprios materiais utilizados na confecção do abrigo onde a carga térmica radiante é menor (BAÊTA \& SOUZA, 1997).

A maior restrição à produção zootécnica em países de clima quente encontra-se na própria dificuldade de que os animais foram geneticamente desenvolvidos e alojados em condições ou conceitos provenientes de climas mais amenos. Daí a necessidade de instalações adaptadas, com características construtivas que garantam o mínimo de conforto, permitindo ao animal abrigado desenvolver todo seu potencial genético (ARCARO, 2000). O investimento em climatização seria uma alternativa viável e disponível para o produtor rural, sendo importante para esse ter a certeza de estar investindo o seu capital de maneira rentável (MARTELLO, 2002).

Esse investimento deverá ser capaz de estimar aspectos relacionados não somente à rentabilidade, mas também à capacidade de pagamento e tempo necessário para recuperar o capital investido (ROMANINI et al., 2002).

O objetivo do trabalho foi analisar o investimento em climatização para alojamentos de free-stall para bovinos de leite.

\section{MATERIAL E MÉTODOS}

O experimento foi conduzido na Fazenda Paraíso, localizada próximo à cidade de Santo Antônio do Jardim - SP, cuja a latitude é $22^{\circ} 14^{\prime} \mathrm{S}$, longitude $46^{\circ} 74^{\prime}$, altitude de $750 \mathrm{~m}$, temperatura máxima média anual $33^{\circ} \mathrm{C}$ e a mínima média anual $22^{\circ} \mathrm{C}$. A umidade relativa média anual de $75 \%$.

Foram utilizadas 470 vacas de um rebanho comercial de 1.000 cabeças, com características genéticas e morfológicas homogêneas, da raça Holandesa, de alta produção e puras por cruza nos dois períodos estudados, e alojadas em dois galpões do tipo free-stall.

As vacas receberam a mesma dieta alimentar de rotina da fazenda, como silagem de milho, farelo de soja, grão de milho moído e minerais, que foram fornecidos de maneira a atender a todas as exigências nutricionais para a manutenção da produção de leite. Os alimentos foram fornecidos 
diretamente nos comedouros, duas vezes ao dia, sendo a primeira refeição fornecida pela manhã e a outra após a segunda ordenha, sendo esses fornecidos diretamente no cocho dentro das instalações.

As vacas foram ordenhadas duas vezes por dia - às 6 e às $15 \mathrm{~h}$-, e os dados de produções individuais foram anotados em fichas e depois transferidos para o computador, no qual ficaram armazenados para análise posterior.

Foram registradas as temperatura $\left({ }^{\circ} \mathrm{C}\right)$ do globo negro e do bulbo seco. A coleta de dados foi realizada por meio de leitura contínua de "dataloggers" marca Testo ${ }^{\circledR}$ nos períodos de setembro, outubro e novembro de 2000, sem climatização, e nos períodos de setembro, outubro e novembro de 2001, usando climatização.

Os galpões eram totalmente abertos, com cobertura de telhas metálicas, pilares de concreto prémoldado e o piso de concreto ranhurado para melhor escoamento da água de limpeza, com dimensões de $85,0 \mathrm{~m}$ de comprimento por 29,4 $\mathrm{m}$ de largura e pé-direito de 3,6 $\mathrm{m}$.

Os ventiladores foram colocados a uma altura de 3,0 m e alternados nos pilares internos dos galpões para que ficassem mais próximos dos animais. O total de ventiladores foi de 32 em cada galpão, com potência de $0,5 \mathrm{cv}$, com uma hélice de 4 pás de $40 \mathrm{~cm}$ e uma vazão de $150 \mathrm{~mL} \mathrm{~min}^{-1}$. O sistema de ventilação era acionado quando a temperatura interna atingia $25^{\circ} \mathrm{C}$.

A nebulização era composta por quatro bicos de nebulizadores acoplados aos ventiladores com uma vazão de $600 \mathrm{~mL} \mathrm{~min}^{-1}$. Os nebulizadores eram acionados por um termostato de bulbo úmido, quando a temperatura interna atingia $27^{\circ} \mathrm{C}$, ligando e desligando a cada 60 segundos, bem como quando a umidade relativa se encontrava até $85 \%$.

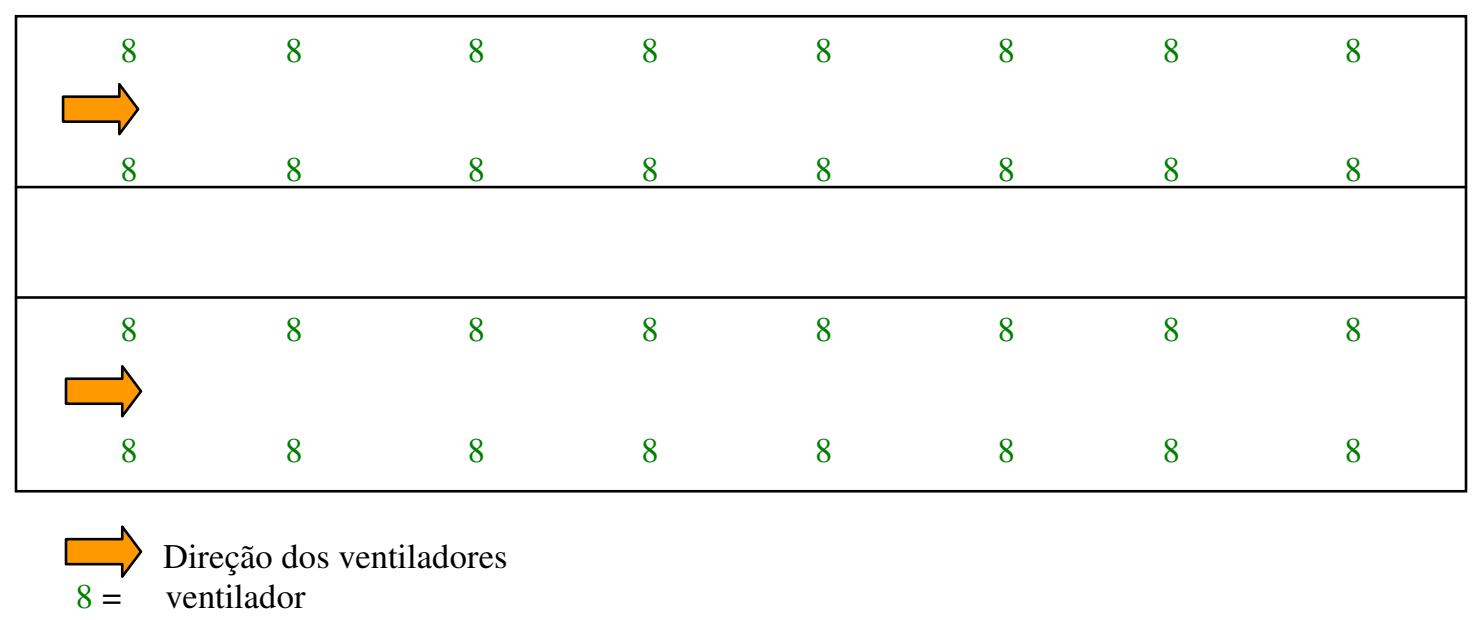

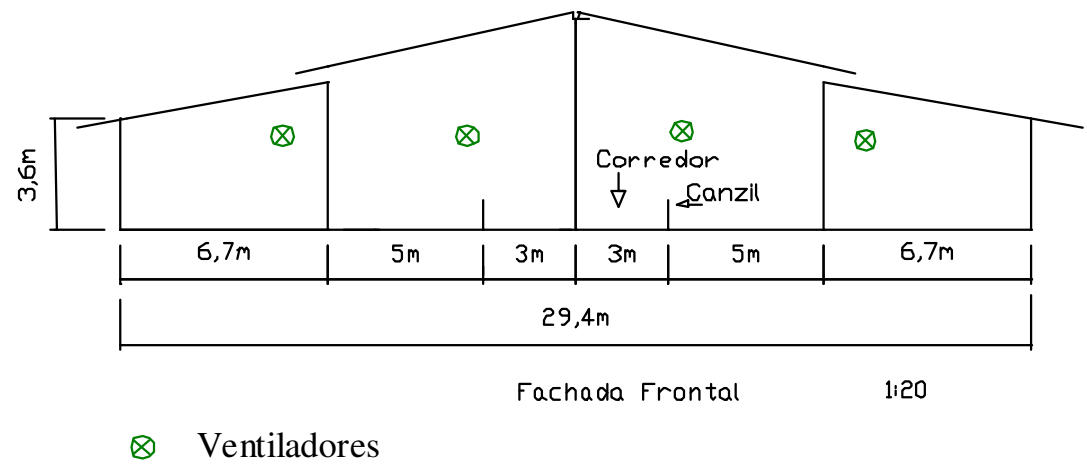

FIGURA 1. Esquema da instalação e localização dos ventiladores. 


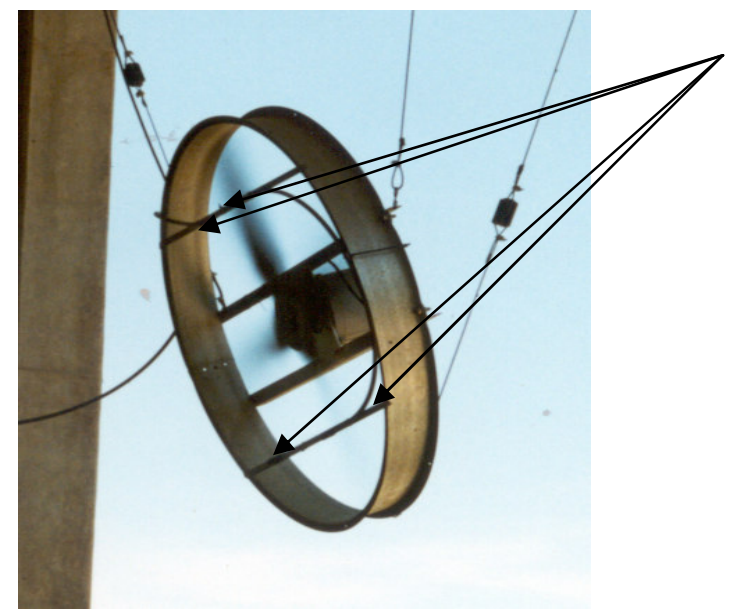

4 bicos de nebulizadores diametralmente opostos

FIGURA 2. Detalhe dos nebulizadores acoplados ao ventilador.

Depois de instalados os ventiladores e nebulizadores, foram avaliados estatisticamente os seguintes tratamentos:

T1 - vacas alojadas em estábulo free-stall, sem recursos de climatização, e

T2 - vacas alojadas em estábulo free-stall, com ventilação e linhas de nebulização.

Os dados ambientais foram registrados e tomados como parâmetros para avaliação e as respostas do ambiente físico aos tratamentos, utilizando os índices de produção média de leite por vaca, como fator de resposta.

\section{Índice de temperatura e umidade (ITU)}

Foi calculado por meio da fórmula desenvolvida por BACCARI et al. (1983).

$\mathrm{ITU}=\mathrm{Ts}+0,36 \mathrm{To}+41,2$

em que,

Ts - temperatura do termômetro de bulbo seco, ${ }^{\circ} \mathrm{C}$, e

To - temperatura do ponto de orvalho, ${ }^{\circ} \mathrm{C}$.

\section{Índice de temperatura de globo e umidade (ITGU)}

Foi calculado por meio da fórmula desenvolvida por BUFFINGTON et al. (1981).

$\mathrm{ITGU}=\mathrm{Tg}+0,36 \mathrm{To}+41,5$

em que,

$\mathrm{Tg}$ - temperatura do termômetro de globo negro, e

To - temperatura do ponto de orvalho.

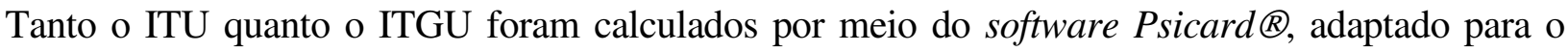

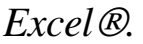

Os resultados foram submetidos à análise de variância para determinar a significância das variáveis nos diferentes tratamentos, utilizando o software Minitab ${ }^{\circledR}$. Foram realizados testes não-paramétricos para comparação de medianas a fim de determinar o intervalo de confiança. Esses testes são mais adequados para os casos em que as distribuições dos dados diferem de distribuição normal. Uma das vantagens de realizar esse teste de medianas é de não haver exigências quanto à distribuição dos dados em relação à simetria e à normalidade. 
O preço do leite in natura também foi cotado em agosto de 2002. O cálculo do investimento foi realizado pela planilha de cálculo do programa Excell $\AA$, após um levantamento cuidadoso dos dados referentes aos equipamentos utilizados na climatização e preços cotados em outubro de 2002. Foi realizada uma conversão para o dólar cotado no dia $1^{\underline{0}}-10-2002$.

Para a obtenção dos custos referentes ao investimento, foram considerados apenas os acréscimos de investimentos necessários para a climatização do ambiente, uma vez que os demais componentes já eram existentes na fazenda.

O custo fixo refere-se ao custo de depreciação, gerado pela razão entre o valor do investimento e a vida útil, e ao custo da manutenção dos equipamentos. Os gastos com a manutenção dos equipamentos de nebulização consideram a troca de bicos e filtros necessários para o período de um ano, de acordo com especificações do fabricante.

O custo variável considera os gastos com energia elétrica e água fornecidos pela fazenda, já calculados o tempo diário de funcionamento dos equipamentos, bem como o consumo de energia dos ventiladores, calculados a partir do tempo que esses equipamentos permaneceram ligados nos períodos mais críticos do dia, ou seja, quando a temperatura interna dos galpões atingiam $25^{\circ} \mathrm{C}$ (temperatura de acionamento dos ventiladores).

Para a análise da receita, considerou-se a produção de leite das vacas pertencentes ao grupo com climatização, considerando o aumento médio diário da produção/vaca, projetado para 470 vacas.

\section{RESULTADOS E DISCUSSÃO}

Os dados da avaliação física do ambiente de alojamento foram coletados nos seguinte horários: para temperatura mínima (Tmín) às 7 h e temperatura máxima (Tmáx) às 14 h, temperatura do globo negro máxima (Tgmáx) às $14 \mathrm{~h}$. A umidade relativa média foi medida nos mesmos horários, sendo os resultados apresentados na Tabela 1.

TABELA 1. Avaliação física do ambiente referente aos dois períodos estudados.

\begin{tabular}{lcccc}
\hline Ambiente & Tmín $\left({ }^{\circ} \mathrm{C}\right)$ & Tmáx $\left({ }^{\circ} \mathrm{C}\right)$ & Tgmáx $\left({ }^{\circ} \mathrm{C}\right)$ & URmédia $(\%)$ \\
\hline T1 (sem climatização) & $19,20 \mathrm{~b}$ & $29,33 \mathrm{~b}$ & $39,79 \mathrm{~A}$ & $61,70 \mathrm{~A}$ \\
T2 (com climatização) & $18,47 \mathrm{a}$ & $26,47 \mathrm{a}$ & $37,77 \mathrm{~B}$ & $65,90 \mathrm{~B}$ \\
\hline
\end{tabular}

a e b: $\alpha=0,01 ; \quad$ A e B: $\alpha=0,05$

De acordo com as análises estatísticas realizadas nos tratamentos $\mathrm{T} 1$ e T2, os valores de temperatura mínima $\left(\right.$ Tmín $\left.{ }^{\circ} \mathrm{C}\right)$ e temperatura máxima $\left(\right.$ Tmáx ${ }^{\circ} \mathrm{C}$ ) são diferentes a um nível de $\alpha=0,01$. Já para temperaratura do globo máxima $\left(\operatorname{Tgmáx}^{\circ} \mathrm{C}\right)$ e umidade relativa média (URmédia $\%$ ), são diferentes a um nível de $\alpha=0,05$. As temperaturas máximas e mínimas para os animais com climatização estão dentro dos parâmetros estudados por MÜLLER (1982) e THATCHER \& COLLIER (1982), os quais afirmaram que, quando a temperatura ultrapassa o valor de $26,7^{\circ} \mathrm{C}$, ocorre considerável declínio na produção de leite, e o balanço calórico é prejudicado, assim como o consumo alimentar. A temperatura do globo negro máxima (Tgmáx) foi menor para o grupo T2; isso significa que esses animais estavam mais confortáveis dentro do ambiente climatizado do que o grupo T1 sem nenhum tipo de climatização, uma vez que, para KELLY \& BOND (1995), a temperatura de globo negro é uma indicação dos efeitos combinados de temperatura do ar, temperatura radiante e velocidade do vento, isto é, representa a exposição a todas as fontes de radiação existentes no ambiente. Os dados de produção foram analisados nos dois períodos para T1 e T2 com o objetivo de analisar a diferença entre os dois tratamentos e se essa diferença foi significativa. Foram analisadas as respostas dos tratamentos comparados à produção média de leite $(\mathrm{kg} / \mathrm{dia} / \mathrm{vaca})$ para os dois grupos (T1 e T2). Para o grupo T1, a produção média de leite foi de $28,50 \mathrm{~kg} / \mathrm{dia} / \mathrm{vaca}$ e, para o grupo T2, foi de 32,65 kg/dia/vaca, ficando evidenciado que houve um acréscimo de $4,2 \mathrm{~kg} / \mathrm{dia} / \mathrm{vaca}$. 
DAMASCENO \& TARGA (1997) também obtiveram resultados satisfatórios de produção de vacas leiteiras sob efeito das condições climáticas, afirmando que o conhecimento das relações funcionais existentes entre o animal e o meio ambiente facilitam a adoção de técnicas que permitem elevar a eficiência produtiva. Foi realizada uma análise econômica utilizando os dados de produção referentes às vacas do experimento. Nas Tabelas 2; 3; 4 e 5, apresentam-se a análise dos investimentos e o retorno de capital investido.

Na Tabela 2, o investimento inicial foi de US\$ 8.100,35 (cotação do dólar: R \$ 3,66 = US\$ 1,00 do dia $1^{0}$-10-2002). Essas análises foram efetuadas, levando-se em consideração os galpões, nos períodos de setembro a novembro de 2001.

TABELA 2. Investimento e custos das instalações com nebulizadores e ventiladores.

\begin{tabular}{lrrrrr}
\hline Investimento Inicial & Quantidade & $\begin{array}{c}\text { Valor Unitário } \\
\text { (US\$) }\end{array}$ & Vida Útil & $\begin{array}{c}\text { Valor Total } \\
\text { (US\$) }\end{array}$ & Depreciação \\
\hline Ventiladores & 64 & 104,71 & 15 & $6.701,64$ & 446,78 \\
Bicos nebulizadores & 256 & 1,47 & 1 & 376,31 & 376,31 \\
Bombas de água & 2 & 129,23 & 10 & 258,47 & 25,85 \\
Manômetros & 2 & 16,39 & 10 & 32,79 & 3,28 \\
Canos & 28 & 1,91 & 10 & 53,55 & 5,35 \\
Filtros & 2 & 32,79 & 1 & 65,57 & 65,58 \\
Instalação elétrica - materiais & 2 & 87,43 & 20 & 174,86 & 8,74 \\
Instalação hidráulica - materiais & 2 & 81,97 & 20 & 163,93 & 8,20 \\
Mão-de-obra & 2 & 136,61 & 20 & 273,22 & 13,66 \\
\hline Total US\$ & \multicolumn{5}{c}{$8.100,35$} \\
\hline Depreciação mensal US\$
\end{tabular}

Na Tabela 3, apresenta-se o custo variável, sendo o cálculo baseado em ventiladores ligados por cinco horas, das 10 às 15 h, sendo esses horários considerados como mais críticos do dia. Das leituras dos "dataloggers", foram consideradas apenas as temperaturas mínimas e máximas nos períodos estudados. Os ventiladores eram ligados quando a temperatura interna dos barracões atingia $25^{\circ} \mathrm{C}$ e os nebulizadores a $27^{\circ} \mathrm{C}$. Quanto ao consumo de água, os cálculos foram baseados em três horas de funcionamento e também considerando os horários mais críticos do dia - das 12 às 15 h - quando a umidade também está em valores mais baixos.

TABELA 3. Custo variável.

\begin{tabular}{lccc}
\hline Custo Variável & Quantidade de Galpões & Valor Unitário & Valor Total \\
\hline Consumo de água & 2 & 113,14 & 226,28 \\
Energia elétrica & 2 & 45,88 & 91,76 \\
\hline Total US\$ por mês & & & 318,04 \\
\hline
\end{tabular}

TABELA 4. Valor monetário arrecadado durante o mês

Número de Animais

Aumento de produção/média diária/vaca

Total de leite produzido/dia

Total de leite produzido/mês

Preço do leite in natura

Valor monetário/mês

\section{0}

$4,2 \mathrm{~kg}$ de leite

$1.974 \mathrm{~kg}$ de leite ao dia

59.220 ao por mês

US\$ 0,08 por $\mathrm{kg}$ de leite

US\$ 4.692,30 ao mês


A produção média diária aumentou em aproximadamente $4,2 \mathrm{~kg}$ de leite/vaca/dia, com um aumento de leite diário de $1.974 \mathrm{~kg}$, obtendo, no mês, um total de $59.220 \mathrm{~kg}$ de leite a mais na produção total da granja. Seguindo essa linha de raciocínio, o leite no mês 8-2002, foi cotado a US\$ 0,08. Na Tabela 5, pode-se observar o tempo que o produtor levou para retornar o seu investimento em climatização.

TABELA 5. Tempo de retorno do investimento.

\begin{tabular}{lrr}
\hline & Mensal & Diário \\
\hline Depreciação & 79,48 & 2,65 \\
Custo variável & 318,04 & 10,60 \\
Produção de Leite & $4.692,30$ & 156,41 \\
\hline Lucro do produtor & $4.294,77$ & 143,16 \\
\hline Investimento inicial & $8.100,35$ & \\
\hline Total de dias para o retorno de investimento & 57 dias & \\
\hline
\end{tabular}

O valor recebido pela venda do leite durante o mês foi de US\$ 4.692,30; subtraindo-se desse valor os custos variáveis e a depreciação, tem-se o valor do lucro real obtido pelo produtor. Por meio da razão entre o custo do investimento e valor monetário em dias (lucro), foi possível calcular o período de retorno do capital investido pelo produtor, em 57 dias.

\section{CONCLUSÕES}

Houve aumento significativo na produção de média diária de leite por vaca com o uso da climatização. A produção média de leite do grupo T2 aumentou aproximadamente 4,2 $\mathrm{kg}$ de leite/dia/vaca, sendo esse aumento conferido ao ambiente favorável para os animais alojados. Concluiuse, também, que é satisfatório e lucrativo o investimento em climatização para bovinos de leite, além de contribuir para o conforto térmico e, consequientemente, para a produtividade.

\section{REFERÊNCIAS BIBLIOGRÁFICAS}

ARCARO, I.J. Avaliação da influência de ventilação e aspersão em coberturas de sombrite para vacas em lactação. 2000. 81 f. Tese (Doutorado em Construções Rurais e Ambiência) - Universidade Estadual de Campinas, Campinas, 2000.

BAÊTA, F.C.; SOUZA, C.F. Ambiência em edificações rurais: conforto animal. Viçosa: UFV, 1997. $246 \mathrm{p}$.

DAMASCENO, J.C.; TARGA, L.A. Definição de variáveis climáticas na determinação da resposta de vacas holandesas em um sistema "free- stall". Energia na Agricultura, Botucatu, v.12, n.2, p.12-25, 1997.

IBGE. 2001. Anuário estatístico. Disponível em: <http://www.ibge.gov.br> Acesso em: 15 março 2002.

KELLY, C.F.; BOND, T.E. Bioclimatic factors and their measurement. Washington: National Academy of Sciences. 1995.

MARTELLO, L.S. Diferentes recursos de climatização e sua influência na produção de leite, na termorregulação dos animais e no investimento das instalações. 2002. 85 f. Dissertação (Mestrado em Qualidade e Produtividade Animal) - Universidade de São Paulo, Pirassununga, 2002.

MÜLLER, P.B. Bioclimatologia aplicada aos animais domésticos. 2.ed. Porto Alegre: Sulina, 1982. $158 \mathrm{p}$. 
ROMANINI, C.E.; NÄÄS, I.A.; MUNIZ, I.R. Análise do investimento em climatização para matrizes na maternidade e seu efeito no desempenho de leitões. In: CONGRESSO LATINO-AMERICANO DE SUINOCULTURA, 2002, Foz de Iguaçu. Anais... CD-ROM.

THATCHER, W.; COLLER. R.J. Effect of heat on animal productivity. In: HAND BOOK of Agricultural Production. Ed. M. RECHA- CIGL, 1982. p.77-105.

VILELA, D. Leite: bom para a saúde e melhor ainda para a economia brasileira. Disponível em: <http://cnpgl.embrapa.br/artigos/leite.html> Acesso em: 05 julho 2002. 